\title{
Insilico Molecular Docking of some Isolated Selected Compounds of Lantana Camera against Alzheimer's Disease
}

Nishan Chakrabarty ${ }^{1,2}$, Alamgir Hossain ${ }^{3}$, Jackie Barua ${ }^{2,4}$, Himadri Kar $^{5}$, Milonuzzaman $^{1}$, Suraya Akther ${ }^{6}$, Abdullah Al Mahabub7 , Fatema Sharmin ${ }^{7}$, Ameerul Islam ${ }^{8}$ and Mohuya Majumder*2,9

${ }^{1}$ Department of Pharmacy, Jagannath University, Bangladesh

${ }^{2}$ Drug Discovery Department, GUSTO A Research Group, Bangladesh

${ }^{3}$ Department of Chemistry, Jahangirnagar University, Dhaka-1342, Bangladesh

${ }^{4}$ Comilla Medical College, Faculty of Medicine, University of Chittagong, Bangladesh

${ }^{5}$ Department of Cardiovascular and Thoracic Surgery, National Institute of Cardiovascular Disease(NICVD), Bangladesh

${ }^{6}$ Department of Pharmacy, Stamford University, Bangladesh

${ }^{7}$ Department of Pharmacy, Atish Dipankar University of Science and Technology, Bangladesh

${ }^{8}$ Department of Pharmacy, International Islamic University Chittagong, Bangladesh

${ }^{9}$ Department of Pharmacy, East West University, Bangladesh

Received: 制: December 10, 2018; Published: 制: December 18, 2018

${ }^{*}$ Corresponding author: Mohuya Majumder, Department of Pharmacy, East West University, Bangladesh

\begin{abstract}
Lantana Camera (L.) (Family-Verbenaceae) is commonly known as Chotra, is found in fallow lands throughout Bangladesh. The plant has used for carminative, astringent, tonic properties and uterine infection by the tribal in Khagrachari, Bangladesh. Our aim of the study to performed molecular docking studies to identify potential binding affinities of the phytocompounds from Lantana Camera (L.), namely 1-hexanol and 1-octen3-ol towards Ach and BACE1 for searching of lead molecule against Alzheimer's disease. A wide range of docking score found during molecular docking by Schrodinger. 1-hexanol and 1-octen-3-ol showed the docking score respectively $-2.291 \mathrm{kj} / \mathrm{mol}$ and $-2.465 \mathrm{kj} / \mathrm{mol}$ against Ach \& $-0.948 \mathrm{kj} /$ $\mathrm{mol}$ and $-1.267 \mathrm{kj} / \mathrm{mol}$ against BACE1. Between all the compounds 1-octen-3-ol showed best docking score towards Ach \& BACE1. So, 1-octen-3-ol is the best compound for Ach and BACE1 enzyme inhibition, as it possessed best value in Molecular docking. Further in vivo investigation need to identify Ach \& BACE1 enzyme inhibitory activity of isolated compounds from L.Camera (L.).
\end{abstract}

Keywords: Lantana Camera (L.); Ach; BACE1; Molecular docking; 1-octen-3-ol

\section{Introduction}

Alzheimer's disease (AD) is the most common cause of dementia and is a progressive neurodegenerative disorder [1,2]. It is characterized by histopathological changes, designated as senile plaques and fibrillary deposits, which ultimately lead to the death of neuronal cells in the cerebral cortex of the brain [3-5]. Alzheimer's disease is the most frequent cause of dementia in Western societies. In the US, approximately 5.5 million people are affected, and the prevalence worldwide is estimated to be as high as 24 million. In both established and developing nations are rapidly aging, the frequency is expected to double every 20 years until $2040[6,7]$. The familial form of AD is rare, affecting less than five percent of $\mathrm{AD}$ patients and has been associated with mutations of Presenilin 1 (PSEN1), Presenilin 2 (PSEN2) and Amyloid Precursor Protein (APP) [8]. These mutations result in incorrect cleavage of the protein, producing a deposited protein of amyloid- $\beta(A \beta)$ that is more likely to form plaques $[5,9]$.

Alzheimer's disease is characterized by progressive dementia beginning in middle to late life, with death occurring an average 
of 8-10 years after diagnosis. The greatest known risk factor for Alzheimer's is increasing age. Most individuals with the disease are 65 and older. Another risk factor is family history. Research has shown that those who have a parent, brother or sister with Alzheimer's are more likely to develop the disease than individuals who do not. The clinical manifestations of the disease are extremely variable, with symptoms including memory loss, confusion, personality changes, impaired coordination and speech problems [2,10-12].

Lantana camara Linn. (Family: Verbenaceae) is a pantropical weed, affecting pastures, orchards and native forests in about 70 countries worldwide [13]. It also known as Chotra (Bengali) [14]. Folk healers in Asia and South America have used lantana species including Lantana camara for centuries to treat various human ailments such as dermatological and gastrointestinal diseases, tetanus, malaria and tumors [15]. Traditional healers have used lantana species for centuries to treat various diseases. Different parts of L. camara is used for the treatment of various human ailments such as itches, cuts, ulcers, swellings, bilious fever, catarrh, eczema, tetanus, malaria, tumors and rheumatism [16,17].

A productive docking strategy must have the ability to adequately envision the local ligand represent the receptor limiting site (i.e.to find the trial ligand geometry inside a resistance confine) and the related physical-compound sub molecular affiliations [1820]. The aim of this study was to screen out the effective bioactive compounds from Lantana camara Linn., which may be potential inhibitors of Alzheimer's disease in future and may act as a drug which may be effective in preventing the Alzheimer's disease.

\section{Materials and Methods}

\section{In silico Molecular Docking Protein Preparation}

Three-dimensional crystal structure of Ach (PDB id: 2CKM) and BACE1 (PDB id: 4IVT) was downloaded in pdb format from the protein data bank [21]. After that, structure was prepared and refined using the Protein Preparation Wizard of SchrödingerMaestro v10.1. Charges and bond orders were assigned, hydrogens were added to the heavy atoms, selenomethionines were converted to methionines and all waters were deleted. Using force field OPLS_2005, minimization was carried out setting maximum heavy atom RMSD (root-mean-square-deviation) to $0.30 \AA$.

\section{Ligand Preparation}

Compounds were retrieved from Pubchem databases, i.e. 1-hexanol and 1-octen-3-ol. The 3D structures for these were built

Table 1: Docking results of 1-hexanol and 1-octen-3-ol with Ach (PDB id: 2CKM).

\begin{tabular}{|c|c|c|c|c|}
\hline Compound name & Compound ID & Docking score & Glide emodel & Glide energy \\
\hline 1-hexanol & 8103 & -2.291 & -16.347 & -14 \\
\hline 1-octen-3-ol & 18827 & -2.465 & -16.163 & -13.461 \\
\hline
\end{tabular}

Table 2: Docking results of 1-hexanol and 1-octen-3-ol with BACE1 (PDB id: 4IVT).

\begin{tabular}{|c|c|c|c|}
\hline Compound name & Compound ID & Docking score & Glide emodel \\
\hline 1-hexanol & 8103 & -0.948 & -17.235 \\
\hline 1-octen-3-ol & 18827 & -1.267 & -16.821 \\
\hline
\end{tabular}

Cite this article: Nishan C, Alamgir H, Jackie B, Himadri K, M, Suraya A, Abdullah Al Mah, Fatema S, Ameerul I, Mohuya M. Insilico Molecular Docking of some Isolated Selected Compounds of Lantana Camera against Alzheimer's Disease. Biomed J Sci \& Tech Res 12(2)-2018. BJSTR. MS.ID.002235. DOI: 10.26717/ BJSTR.2018.12.002235. 


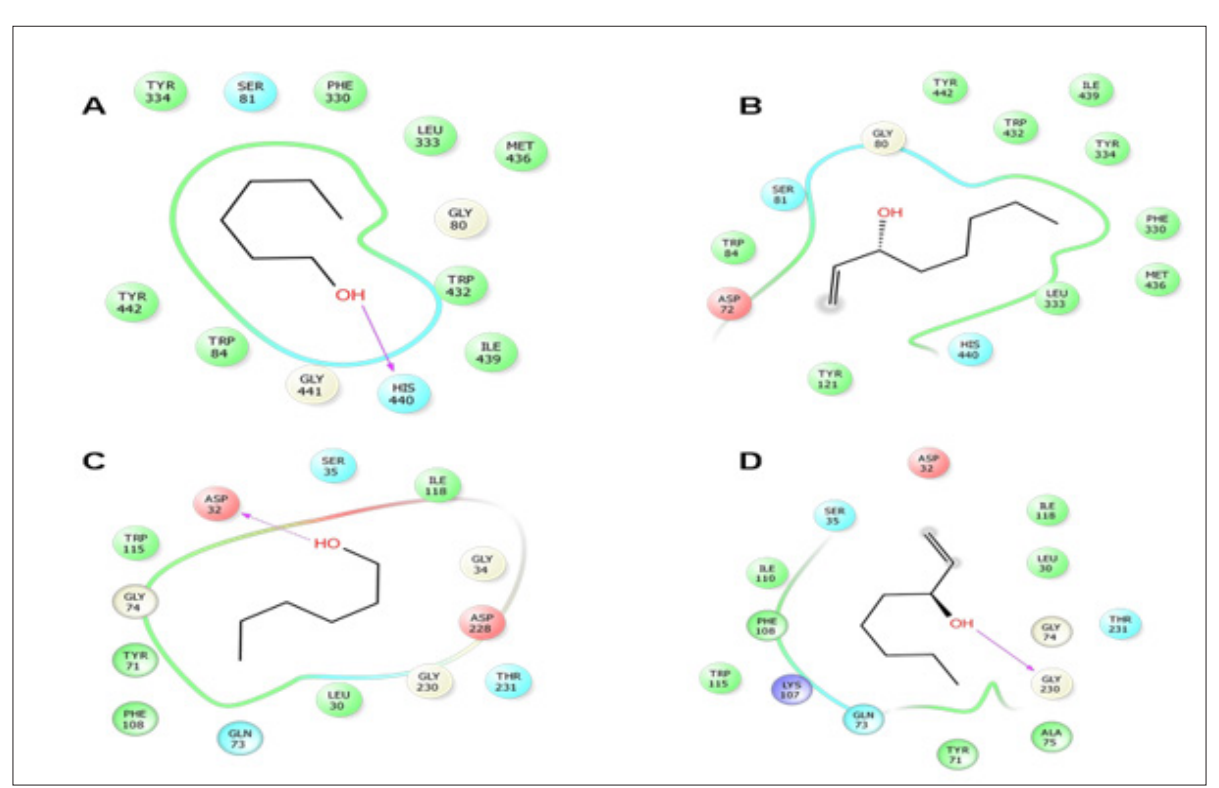

Figure 1: Schematic representation of the interactions between the best pose found for 1-hexanol (A), 1-octen-3-ol (B) with AchE (PDB ID: 2CKM) and, 1-hexanol (C) and 1-octen-3-ol (D) with BACE 1(PDB ID: 4IVT).

The colors indicate the residue (or species) type: Red-acidic (Asp, Glu), Green-hydrophobic (Ala, Val,Ile, Leu, Tyr, Phe, Trp, Met, Cys, Pro), Purple-basic (Hip, Lys, Arg), Blue-polar (Ser, Thr, Gln, Asn, His, Hie, Hid), Light gray-other (Gly, water), and Darker graymetal atoms. Interactions with the protein are marked with lines between ligand atoms and protein residues: Solid pink-H-bonds to the protein backbone, Dotted pink-H-bonds to protein side chains, Green-pi-pi stacking interactions, Orange-pi-cation interactions. Ligand atoms that are exposed to solvent are marked with gray spheres. The protein "pocket" is displayed with a line around the ligand, colored with the color of the nearest protein residue. The gap in the line shows the opening of the pocket.

\section{Discussion}

Phytochemicals are plant-derived chemical compounds that have potential properties. A wide range of phytochemicals has been prevented many chronic diseases, like cancers and heart diseases, by mitigating the cellular dysfunctions [26]. Phytochemicals are the most plenteous dietary antioxidants; but various studies performed in animal models or cell culture demonstrated that the antioxidant activity of these compounds is unlikely to be the sole rationalization for their protecting cellular effects. And phytochemicals even have ability to fix the Alzheimer's disease (AD). Thus, looking out new medication for $\mathrm{AD}$ from medicinal plants is not latest. But it is terribly expensive to discover the drugs in laboratory. In silico molecular docking ways will facilitate us to shorten the procedure of drug discovery by choosing the proper drug for the diseases.

The aim of molecular docking is that the accurate prediction of the structure of a ligand inside the constraints of a receptor binding site and to properly estimate the strength of binding.
To explore effective drugs for the treatment of $\mathrm{AD}$, completely different compounds against known and novel targets of AD could be designed and investigated using molecular docking. Presently there's no treatment to prevent or cure AD. However, many approved medicines will treat several the symptoms and cause a modest and temporary improvement in memory.

Targeting the direct reason for neuronal degeneration would represent a rational strategy and hopefully provide higher prospects for the treatment of AD. Many molecules for the abovementioned targets are withdrawn even from the clinical trials either due to their ineffectiveness in human trials or their no specificity for receptors. The brain, being the most complicated organ, is tough in terms of its structural accessibility and therefore the presence of the blood-brain barrier and so tough for several in vitro molecules to be effective in situ. Therefore, special attention ought to be paid for the development of effective ligands against the potent targets of $\mathrm{AD}$ [24]. In a very nut shell, molecular modeling and docking would be a promising side for novel drug design and would shorten the time span of drug discovery that might be further explored as potential therapeutic interventions for AD. The above result represents that 1-octen-3-ol showed good docking score between two compounds against both Ach and BACE1. So, 1-octen-3-ol is the best compounds for Ach and BACE1 enzyme inhibition, as it possessed best value in Molecular docking.

\section{Conclusion}

The present study revealed that between the compounds 1-octen-3-ol showed best docking score. Further in vivo investigation needs to identify Ach and BACE1 enzyme inhibitory activity of isolated compounds from L. camara. 


\section{References}

1. Saifadini R, Tajadini H, Choopani R, Mehrabani M, Kamalinegad M, et al. (2016) Perception of Alzheimer disease in Iranian traditional medicine. Iran Red Crescent Med J18(3).

2. Tilley L, Morgan K, Kalsheker N (1998) Genetic risk factors in Alzheimer's disease. Mol Pathol 51(6): 293-304.

3. Mattsson N, Zetterberg H, Hansson O, Andreasen N, Parnetti L, et al (2009) CSF biomarkers and incipient Alzheimer disease in patients with mild cognitive impairment. Jama 302(4): 385-393.

4. Hossini AM, Megges M, Prigione A, Lichtner B, Toliat MR, et al. (2015) Induced pluripotent stem cell-derived neuronal cells from a sporadic Alzheimer's disease donor as a model for investigating AD-associated gene regulatory networks. BMC Genomics 16(1): 84.

5. Benedet AL, Labbe A, Lemay P, Zimmer ER, Pascoal TA, et al. (2017) CSF biomarkers and incipient Alzheimer disease in patients with mild cognitive impairment. Neurobiol Aging 6: 643-648.

6. Reitz C, Brayne C, Mayeux R (2011) Epidemiology of Alzheimer disease. Nat Rev Neurol 7(3):137-152.

7. Mayeux R, Stern Y (2012) Epidemiology of Alzheimer disease. Cold Spring Harb Perspect Med 2(8).

8. Cruts M, van Duijn CM, Backhovens H, Van Den BA, Wenhert A, et al. (1998) Estimation of the genetic contribution of presenilin-1 and-2 mutations in a population-based study of presenile Alzheimer disease. Hum Mol Genet 7(1): 43-51.

9. Selkoe DJ (2001) Alzheimer's disease: genes, proteins, and therapy. Physiol Rev 81(2): 741-766.

10. Rosen WG, Mohs RC, Davis KL (1984) A new rating scale for Alzheimer's disease. Am J Psychiatry 141(11): 1356-1364.

11. Aarsland D, Andersen K, Larsen JP, Lolk A (2003) Prevalence and characteristics of dementia in Parkinson disease: An 8-year prospective study. Arch Neurol 60(3): 387-392.

12. Hardy J, Selkoe DJ (2002) The amyloid hypothesis of Alzheimer's disease: Progress and problems on the road to therapeutics. Science 297(5580): 353-356.

13. Munir AA (1996) A taxonomic review of Lantana camara $L$. and $L$. montevidensis (Spreng.) Briq. (Verbenaceae) in Australia. J Adelaide Bot Gard 17:1-27.

\section{ISSN: 2574-1241}

DOI: $10.26717 /$ BJSTR.2018.12.002235

Mohuya Majumder. Biomed J Sci \& Tech Res

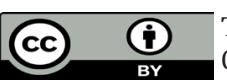

This work is licensed under Creative

Commons Attribution 4.0 License

Submission Link: https://biomedres.us/submit-manuscript.php
14. Ghani A (1998) Medicinal Plants of Bangladesh: Chemical Constituents and Uses. Asiatic society of Bangladesh pp. 467.

15. Pour BM, Sasidharan S (2011) In vivo toxicity study of Lantana camara. Asian Pac J Trop Biomed 1(3): 230-232.

16. Abou-Karam M, Shier WT (1990) A simplified plaque reduction assay for antiviral agents from plants. Demonstration of frequent occurrence of antiviral activity in higher plants. J Nat Prod 53(2): 340-344.

17. Shier WT (1990) A simplified plaque reduction assay for antiviral agent from plants. Demonstration of frequent occurrence of antiviral activity in higher plants. J Nat Prod 53(2): 340-344.

18. Oshiro C, Bradley EK, Eksterowicz J, Evensen E, Lamb ML, et al. (2004) Performance of 3D-database molecular docking studies into homology models. J Med Chem 47(3): 764-767.

19. Arun Y, Saranraj K, Balachandran C, Perumal PT (2014) Novel spirooxindole-pyrrolidine compounds: Synthesis, anticancer and molecular docking studies. Eur J Med Chem 74: 50-64.

20. Lu S-H, Wu JW, Liu H-L, Jian HZ, Kung TL, et al. (2011) The discovery of potential acetylcholinesterase inhibitors: a combination of pharmacophore modeling, virtual screening and molecular docking studies. J Biomed Sci 18(1): 8

21. Berman HM, Westbrook J, Feng Z, Gilliland G, Bhat TN, et al. (2000) The protein data bank. Nucleic Acids Res 28(1): 235-242.

22. Friesner RA, Banks JL, Murphy RB, Halqren TA, Klicic JJ, et al. (2004) Glide: A new approach for rapid, accurate docking and scoring. 1. Method and assessment of docking accuracy. J Med Chem 47(7): 1739-1749.

23. Halgren TA, Murphy RB, Friesner RA, Beard HS, Fyre LL, et al. (2004) Glide: A new approach for rapid, accurate docking and scoring. 2. Enrichment factors in database screening. J Med Chem 47(7): 17501759.

24. Kumar A, Nisha CM, Silakari C, Sharma I, Anusha K, et al. (2016) Current and novel therapeutic molecules and targets in Alzheimer's disease. J Formos Med Assoc 115(1): 3-10.

25. Veeramachaneni GK, Raj KK, Chalasani LM, Annamraju SK, JS B, et al. (2015) Shape based virtual screening and molecular docking towards designing novel pancreatic lipase inhibitors. Bioinformatio 11(12): 535542 .

26. Manach C, Mazur A, Scalbert A (2005) Polyphenols and prevention of cardiovascular diseases. Curr Opin Lipidol 16(1): 77-84.

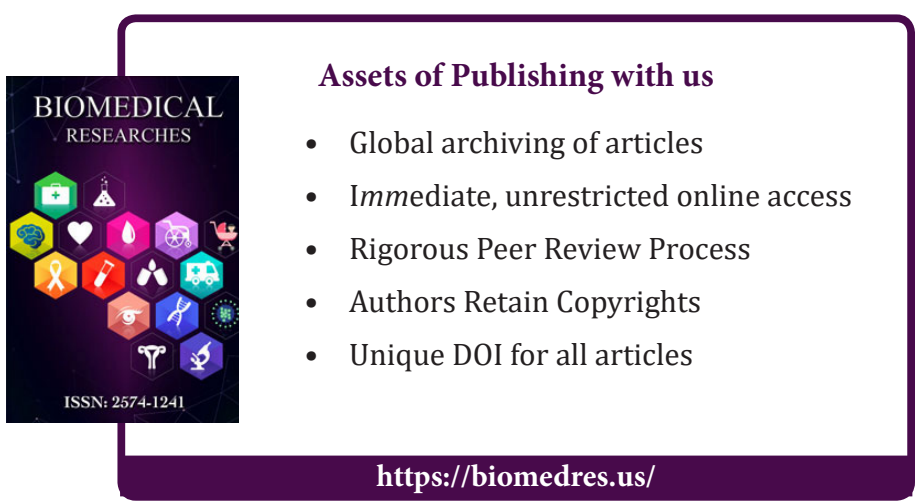

